\title{
Cubic zirconia single crystal growth using shell by skull melting method
}

\author{
Jin-Hwa Jung, Seog-Joo Yon and Jeong-Won Seok ${ }^{\dagger}$ \\ Department of Gem and Precious Metals, Dongshin University, Naju 520-714, Korea \\ (Received April 11, 2013) \\ (Revised May 29, 2013) \\ (Accepted May 31, 2013)
}

\begin{abstract}
In this research, cubic zirconia is synthesized with a refined $\mathrm{CaO}$ from shells as a stabilizer through Skull melting method. The proper process time and concentration are defined by Hydration reaction to produce the refined $\mathrm{CaO}$ after two different treatments using $0.1 \mathrm{~mol} \%$ of $\mathrm{HCl}$ respectively with Cockle shell. The highest purity of $\mathrm{CaO}$ is reached when the shell is immersed in $1 \mathrm{~mol} \% \mathrm{HCl}$. In Hydration reaction step, the pure $\mathrm{Ca}(\mathrm{OH})_{2}$ is produced at $45^{\circ} \mathrm{C}$ for 24 hours. The highest purity of $\mathrm{CaO}$ is measured when the $\mathrm{Ca}(\mathrm{OH})_{2}$ is treated by heat at $1200^{\circ} \mathrm{C}$ for 5 hours. The single crystals are grown through Skull melting method by adding the different contents of the refined $\mathrm{CaO}$ from $10 \mathrm{~mol} \%$ to $30 \mathrm{~mol} \%$ into $\mathrm{ZrO}_{2}$. The frequency of High-frequency oscillator used for Skull melting method is $3.4 \mathrm{MHz}$. The descending speed of the single crystal is $3 \mathrm{~mm} /$ hour. The grown length of the single crystal is $4 \mathrm{~cm}$. As a result of this study, $15 \mathrm{~mol} \%$ of $\mathrm{CaO}$ has the best crystallinity.
\end{abstract}

Key words Cubic zirconia, Skull melting, Stabilizer, Cockle shell, Hydration reaction

\section{스컬용융법에 의한 패각을 이용한 큐빅지르코니아 단결정 성장}

\author{
정진화, 연석주, 석정원 ${ }^{\dagger}$ \\ 동신대학교 보석귀금속학과, 나주, 520-714 \\ (2013년 4월 11일 접수) \\ (2013년 5월 29일 심사완료) \\ (2013년 5월 31일 게재확정)
}

요 약 본 연구에서는 안정화제로, 패각으로부터 정제한 $\mathrm{CaO}$ 를 사용하여 Skull melting법으로 큐빅 지르코니아를 성장 시켰다. 꼬막 패각을 $\mathrm{HCl}$ 을 $0.1 ~ 1 \mathrm{~mol} \%$ 로 1차 처리한 후 수화반응을 거쳐 최적의 처리시간과 농도를 검토하였다. $\mathrm{HCl}$ 을 $1 \mathrm{~mol} \%$ 의 농도로 처리했을 때 가장 순도가 높았으며 수화반응시 $45^{\circ} \mathrm{C}$ 의 온도로 24 시간 동안 반응시킬 때 완전한 $\mathrm{Ca}(\mathrm{OH})_{2}$ 를 얻을 수 있었다. $\mathrm{Ca}(\mathrm{OH})_{2}$ 를 $1200^{\circ} \mathrm{C}$ 에서 5 시간 처리하였을 때 $\mathrm{CaO}$ 의 순도가 가장 높게 측정되었다. 패각으로부터 얻어 진 $\mathrm{CaO}$ 를 $\mathrm{ZrO}_{2}$ 에 첨가하여 함량을 $10 \sim 30 \mathrm{~mol} \%$ 로 변화시켜 Skull melting법으로 단결정을 성장시켰다. Skull melting법에 사용된 고주파 발진기의 주파수는 약 $3.4 \mathrm{MHz}$ 이며 단결정의 하강속도는 시간당 $3 \mathrm{~mm}$ 로 $4 \mathrm{~cm}$ 길이로 성장시켰다. 실험결 과 $\mathrm{CaO}$ 의 함량이 $15 \mathrm{~mol} \%$ 일 때 결정성이 가장 우수했다.

\section{1. 서 론}

지르코니아 $\left(\mathrm{ZrO}_{2}, \mathrm{Zirconia}\right)$ 는 세라믹 재료 중에서도 기계적 특성이 뛰어나고 내식성, 고융점 $\left(2,750^{\circ} \mathrm{C}\right)$, 금속 과 유사한 열팽창율, 낮은 열전도도와 작은 전기저항 등 의 화학적·열적·전기적 특성이 우수하다[1]. $\mathrm{ZrO}_{2}$ 는 베 르누이(verneuil)법, FZ(floating zone)법 및 아크퓨젼(arc fusion)법으로 성장가능 하지만 스컬용융법에 비해 제품

\footnotetext{
Corresponding author

Tel: +82-61-330-3243

Fax: +82-61-330-3253

E-mail: jwseok@dsu.ac.kr
}

의 생산성이나 품질이 우수하지 못하다[2-4]. 따라서 현 재 산업적 생산은 스컬용융법을 이용하고 있다. $\mathrm{ZrO}_{2}$ 는 온도에 따라 상변태가 일어나는데 순수한 $\mathrm{ZrO}_{2}$ 의 경우 정방정상에서 단사정상으로 상전이(Transformer)시 체적 변화가 발생하여 $\mathrm{crack}$ 이 발생한다. 고온에서의 입방구 조(cubic structure)를 상온까지 유지시키기 위한 안정화 제(stabilizer)로는 $\mathrm{CaO}, \mathrm{Sc}_{2} \mathrm{O}_{3}, \mathrm{Y}_{2} \mathrm{O}_{3}$ 등이 사용될 수 있 으나 현재 $\mathrm{Y}_{2} \mathrm{O}_{3}$ 가 가장 많이 사용되고 있다 $[5,6]$. 그러 나 최근 희토류 원소의 자원고갈과 수출규제 등에 의해 원자재 가격이 급상승하고 있기 때문에 종래의 $\mathrm{Y}_{2} \mathrm{O}_{3}$ 를 대체할 수 있는 저가의 새로운 안정화제에 대한 연구가 필요한 실정이다. 한편, 우리나라 남해안 일대에는 매년 
수만톤 이상의 굴, 꼬막, 바지락 등의 패각이 발생하고 있으며 이를 야적하거나 해안에 매립하고 있어 2차, 3 차 환경오염의 원인이 되고 있다. 이중 꼬막은 다른 패각에 비해서 칼슘함량이 높고 백색도가 우수하여 $\mathrm{CaO}$ 자원으 로서의 활용 가치가 높은 것으로 보고되고 있으므로 이 를 재활용할 수 있는 기술개발이 필요하다. 이에 본 연 구에서는 안정화제로 꼬막 패각을 정제 하여 $\mathrm{CaO}$ 를 제 조하고, 제조된 $\mathrm{CaO}$ 를 사용하여 Skull melting 법을 이 용한 큐빅 지르코니아 단결정을 합성하고자 하였다. 또 한 $\mathrm{CaO}$ 순도 및 첨가량의 변화가 큐빅 지르코니아 단 결정 성장에 미치는 영향에 대해서 검토하고, 최적의 $\mathrm{CaO}$ 함량과 조건을 제시하고자 하였다.

\section{2. 연구방법}

꼬막 표면의 불순물 제거를 위해서 일차적으로 패각 표면을 세척한 후 건조하여 $\mathrm{HCl}$ 의 농도를 $0.1 \sim 1 \mathrm{~mol} \%$ 로 변화를 주어 처리하였으며 처리된 꼬막은 $120^{\circ} \mathrm{C}$ 에서 24 시간 건조한 후, $500 \sim 1200^{\circ} \mathrm{C}$ 로 $3 \sim 5$ 시간 소성하여 $\mathrm{CaO}$ 를 제조하였다. 고온 열처리하여 얻어진 $\mathrm{CaO}$ 는, 순 도를 향상시키기 위해 미분쇄 후 $40 \sim 50^{\circ} \mathrm{C}$ 의 온도에서 3 24시간 동안 습식수화반응을 행하였으며 수화반응에 의해 얻어진 $\mathrm{Ca}(\mathrm{OH})_{2}$ 는 $500 \sim 1200^{\circ} \mathrm{C}$ 로 $3 \sim 5$ 시간 소성하 여 $\mathrm{CaO}$ 를 제조하였다. 제조된 $\mathrm{CaO}$ 함량을 $10 \sim 30 \mathrm{~mol} \%$ 로 변화시켜 Skull melting법으로, 2turn coil로 coil turn 수를 고정하였고 이때의 tank condenser는 $2000 \mathrm{pF}$, 고 주파 발진기의 주파수는 약 $3.4 \mathrm{MHz}$ 이다.

\section{3. 결과 및 고찰}

\section{1. 꼬막 패각으로부터의 $\mathrm{CaO}$ 제조}

큐빅 지르코니아를 합성할 때 안정화제로서 굴이나 바 지락에 비해 $\mathrm{CaO}$ 함량이 높고 백색도가 뛰어나며 정제 과정이 용이한 꼬막 패각을 출발물질로 사용하였다 $[7$, 8]. 꼬막 패각의 표면의 불순물을 제거하기 위해 일차적 으로 패각 표면을 브러시로 세척한 후, 정제과정에 들어 갔다. Fig. 1은 $\mathrm{HCl}$ 으로 전처리한 꼬막 패각의 사진을 나타내었으며, $\mathrm{HCl}$ 의 농도는 $0.1 \sim 1 \mathrm{~mol} \%$ 이였다. 그 결 과 $0.1 \mathrm{~mol} \%$ 의 $\mathrm{HCl}$ 농도에서 12 시간 처리한 꼬막 패각 은 처리 전과 비교하였을 때 표면의 불순물들이 대부분 제거 되었으며, $\mathrm{HCl}$ 농도를 $1 \mathrm{~mol} \%$ 로 증가시켰을 경우 에는 표면에 잔존하는 검은색의 불순물은 전혀 관찰되지 않았다.

꼬막 패각으로부터 제조된 $\mathrm{CaO}$ 에 대해서 순도를 향상시
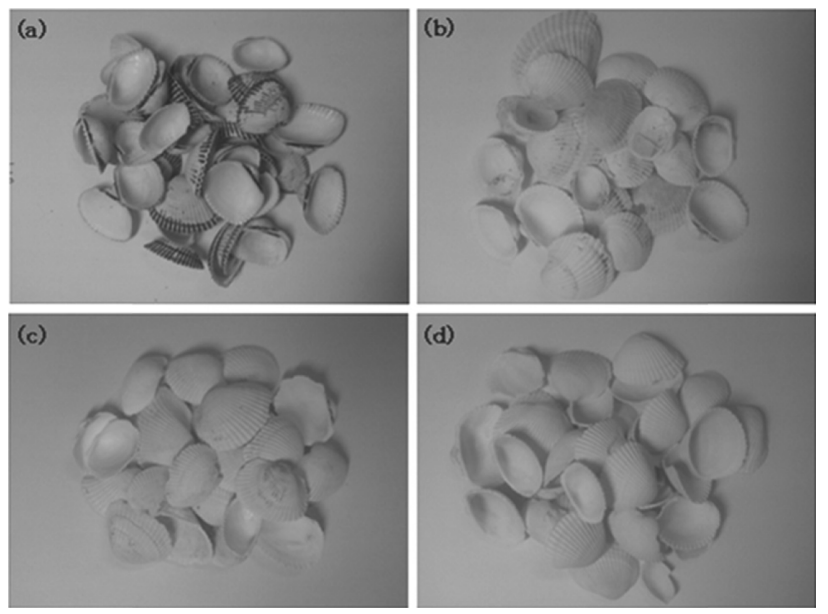

Fig. 1. Photographs of the refinement treated Cockle shell by $\mathrm{HCl}$ : (a) non-treatment, (b) $0.1 \mathrm{~mol} \%$ (c) $0.5 \mathrm{~mol} \%$ and (d) $1 \mathrm{~mol} \%$. Reaction time was fixed for $12 \mathrm{hrs}$.

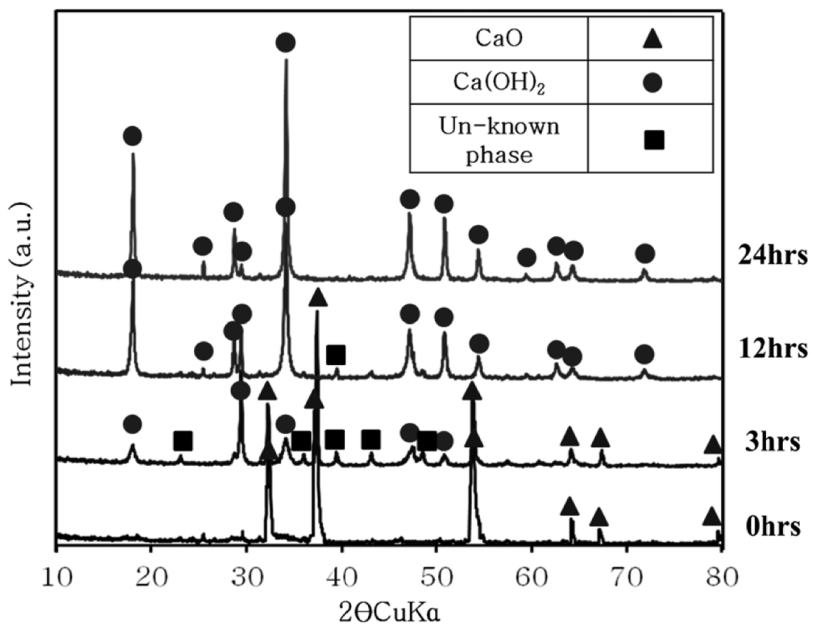

Fig. 2. XRD patterns for hydration reaction of $\mathrm{CaO}$ extracted from Cookle-shell. The temperature of hydration reaction was fixed $45^{\circ} \mathrm{C}$.

키기 위해 습식수화방법을 선택하였다. 수화조건은 $45^{\circ} \mathrm{C}$ 에 서 3 24시간 범위 내에서 행하였다. 그 결과를 Fig. 2에 나타내었다. $\mathrm{CaO}$ 를 3 시간 동안 물과 반응을 시킬 경우, 미 반응물의 $\mathrm{CaO}$ 와 수화된 $\mathrm{Ca}(\mathrm{OH})_{2}$ 및 미지의 결정상 이 혼재된 혼상의 $\mathrm{Ca}(\mathrm{OH})_{2}$ 가 얻어졌다. 반면 반응시간 을 12 시간으로 늘릴 경우, 일부 미지의 결정상이 존재하 였지만 거의 대부분 $\mathrm{Ca}(\mathrm{OH})_{2}$ 로 수화되었으며, 단일상의 $\mathrm{Ca}(\mathrm{OH})_{2}$ 는 24 시간 동안 습식 수화반응시켜 얻을 수 있었 다. Y. Arai에 의하면, $\mathrm{CaO}-\mathrm{H}_{2} \mathrm{O}$ 계 수화반응으로 $\mathrm{Ca}(\mathrm{OH})_{2}$ 의 생성반응은 발열반응으로 간단하지만(식 3-1), 임계점 의 압력과 온도가 없는 상태에서는 다음과 같은 두 단계 에 걸쳐 $\mathrm{Ca}(\mathrm{OH})_{2}$ 가 생성되는 것으로 보고하였다 $[7,8]$.

$$
\begin{aligned}
& \mathrm{CaO}+\mathrm{H}_{2} \mathrm{O} \rightarrow \mathrm{Ca}(\mathrm{OH})_{2} \\
& \mathrm{CaO}+\mathrm{H}_{2} \mathrm{O} \rightarrow\left[\mathrm{CaO} \cdot \mathrm{H}_{2} \mathrm{O}(\mathrm{s})\right]
\end{aligned}
$$


Table 1

Results of ICP analysis for $\mathrm{CaO}$. The $\mathrm{CaO}$ sample used for ICP analysis was prepared by the heat treatment at $1200^{\circ} \mathrm{C}$ for $5 \mathrm{hrs}$ in air using $\mathrm{Ca}(\mathrm{OH})_{2}$ obtained by hydration reaction

\begin{tabular}{lllll}
\hline & & $\begin{array}{l}\text { Concentration } \\
(\text { mol\%) }\end{array}$ & \multicolumn{2}{l}{ Purity (\%) } \\
\cline { 3 - 5 } & & Before & After \\
\hline Non-treatment & & - & $78 \sim 79$ & $82 \sim 83$ \\
Pretreatment & $\mathrm{HCl}$ & 1 & $91 \sim 92$ & $95 \sim 96$ \\
& & 0.5 & $88 \sim 89$ & $92 \sim 93$ \\
& & 0.1 & $87 \sim 88$ & $89 \sim 90$ \\
\hline
\end{tabular}

$\left[\mathrm{CaO} \cdot \mathrm{H}_{2} \mathrm{O}\right](\mathrm{s}) \rightarrow \mathrm{Ca}(\mathrm{OH})_{2}(\mathrm{~s}) \rightarrow \mathrm{Ca}(\mathrm{OH})_{2}(\mathrm{~s})$

즉, 1 단계로 $(3-2)$ 식의 반응이 일어나 $\left[\mathrm{CaO} \cdot \mathrm{H}_{2} \mathrm{O}\right]$ 로 표시되는 흡착수를 함유한 생성물이 순간적으로 생성되 고 2단계로 (3-3)식의 반응에 의해 $\mathrm{Ca}(\mathrm{OH})_{2}$ 가 생성한다. 비록 $\mathrm{CaO}$ 가 $\mathrm{MgO}, \mathrm{BaO}$ 등과 비교하여 용해도가 높기 때문에 대기 중의 수분과 자연 수화반응이 용이하게 일 어나지만 $[9,10]$, 과량의 물이 들어있는 슬러리 상태에서 의 반응은 물에 대한 원료물질의 용해속도가 전체의 반 응속도를 결정하는 용해 율속반응에 해당하기 때문에 완 전하게 $\mathrm{Ca}(\mathrm{OH})_{2}$ 로 수화시키기 위해서는 충분한 시간이 필요하다고 판단된다. Table 1에는 습식 수화방법으로 제조된 $\mathrm{Ca}(\mathrm{OH})_{2}$ 에 대해서 $1200^{\circ} \mathrm{C}$ 에서 5 시간 소성하여 얻어진 $\mathrm{CaO}$ 의 ICP-AES 성분분석 결과를 나타내었다. 먼저, 전처리 및 수화반응 없이 as-received 꼬막 패각을 소성한 결과, $\mathrm{CaO}$ 순도는 78 79\%이였으나, 수화반응 후 소성을 통하여 $82 \sim 83 \%$ 의 순도를 갖는 $\mathrm{CaO}$ 가 제조 되었다. $\mathrm{HCl}$ 로 전처리 한 꼬막 패각을 수화과정 없이 $1200^{\circ} \mathrm{C}$ 에서 5 시간 동안 소성한 $\mathrm{CaO}$ 는, $0.1 \mathrm{~mol} \%$ 에서 87 88\%의 순도를 가지고 있었지만, $\mathrm{HCl}$ 의 농도가 증 가하면서 순도도 향상되었으며, $1 \mathrm{~mol} \%$ 농도에서 92 $91 \%$ 의 값이 얻어졌다. 그리고 수화반응 후에 소성하여 얻어진 $\mathrm{CaO}$ 의 순도는, 수화반응전과 비교하여 $4 \sim 5 \%$ 증가한 95 96\%의 순도를 나타내었다.

\section{2. $\mathrm{CaO}$ 안정화 큐빅 지르코니아 단결정 성장}

꼬막 패각을 정제하여 얻은 $\mathrm{CaO}$ 를 안정화제로 사용하 여 큐빅 지르코니아 단결정을 성장시키기 위하여 work coil의 turn 수를 2turn으로 실험하였다. 이때의 tank condenser는 $2000 \mathrm{pF}$ 이며 주파수는 $3.4 \mathrm{MHz}$ 이다. 꼬막 패각을 정제하여 얻은 $\mathrm{CaO}$ 의 함량을 $10 ~ 30 \mathrm{~mol} \%$ 로 $5 \mathrm{~mol} \%$ 씩 증가시켜 $\mathrm{CaO}$ 함량에 따른 큐빅 지르코니아 의 격자상수, 면간거리, 결정자의 변화를 통해 최적의 $\mathrm{CaO}$ 함량을 찾고자 하였다. Fig. 3과 Fig. 4의 (a)는 $\mathrm{CaO}$ 의 함량을 $10 \mathrm{~mol} \%$ 로 첨가하여 단결정을 성장시킨 잉곳(ingot)과 단결정의 모습으로 결정에 크랙이 다량 존
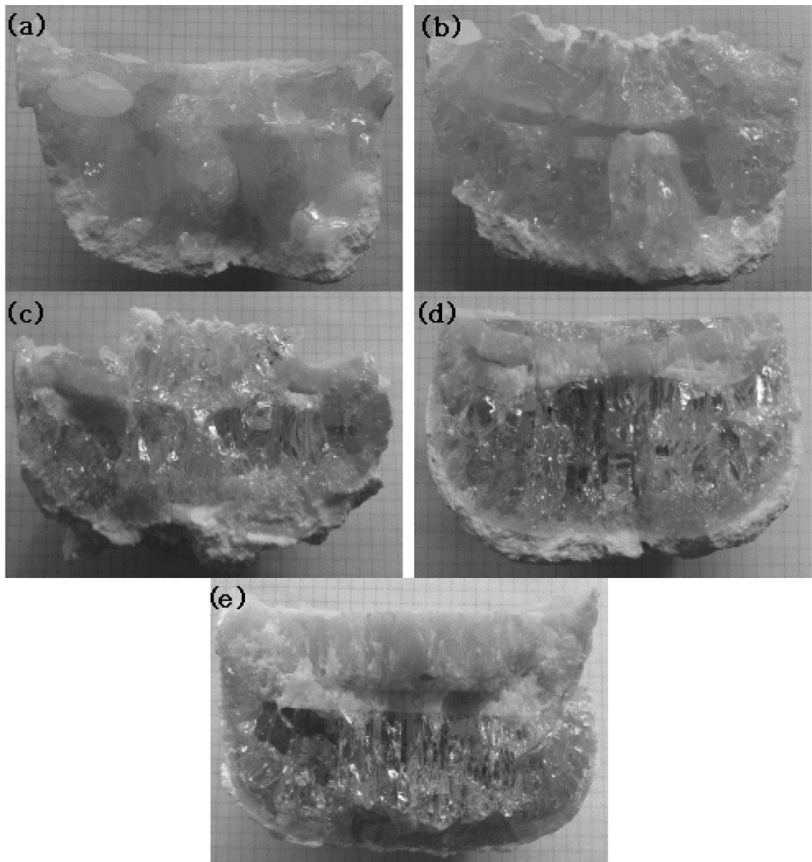

Fig. 3. Ingots of $\mathrm{CaO}$-stabilized cubic zirconia Single crystal grown by skull melting process. (a) $\mathrm{ZrO}_{2}+\mathrm{CaO}(10 \mathrm{~mol} \%$ ), (b) $\mathrm{ZrO}_{2}+\mathrm{CaO}$ (15 mol\%), (c) $\mathrm{ZrO}_{2}+\mathrm{CaO}$ (20 mol\%), (d) $\mathrm{ZrO}_{2}+$ $\mathrm{CaO}(25 \mathrm{~mol} \%)$ and (e) $\mathrm{ZrO}_{2}+\mathrm{CaO}(30 \mathrm{~mol} \%)$.

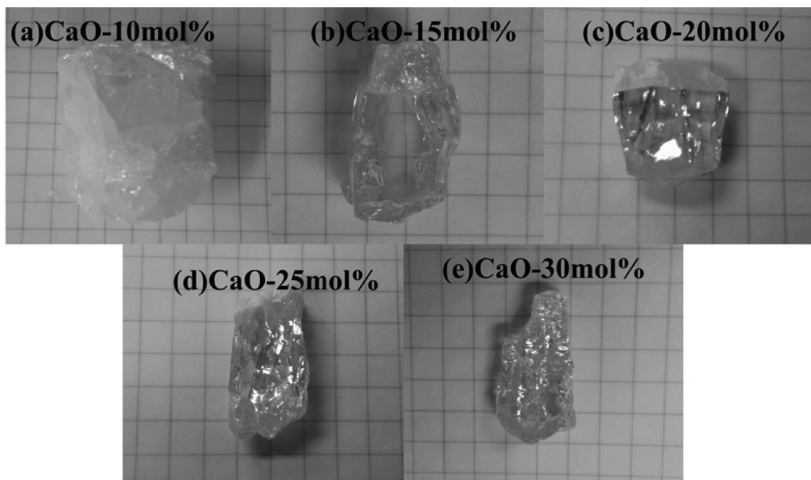

Fig. 4. Cubic zirconia single crystal grows using $\mathrm{CaO}$ prepared from Cokle shell.

재하며 투명도가 좋지 못하여 단결정의 크기는 큰 편이 지만 보석용 큐빅 지르코니아로 사용하기에는 부적합하 다. (b)는 $15 \mathrm{~mol} \%$ 의 $\mathrm{CaO}$ 를 첨가한 것으로 투명도가 $10 \mathrm{~mol} \%$ 로 성장시킨 단결정 보다 결정의 크기는 상대적 으로 작아졌지만 투명도가 뛰어나므로 보석용으로 사용 이 가능하다. (c)는 $\mathrm{CaO}$ 함량이 $20 \mathrm{~mol} \%$ 로 성장시킨 잉곳으로, $15 \mathrm{~mol} \%$ 의 함량으로 성장시킨 단결정과 투명 도가 크게 다르지 않으며 완벽한 투명에 가깝지만 결정의 크기가 급격하게 작아짐을 알 수 있다. (d)는 $25 \mathrm{~mol} \%$ 의 함량으로 성장시킨 큐빅 지르코니아의 잉곳이며 (e)는 $30 \mathrm{~mol} \%$ 의 함량으로 성장시킨 큐빅 지르코니아이다. $\mathrm{CaO}$ 함량이 $15 \mathrm{~mol} \%$ 이상이 되면 투명도는 좋아지지만 성 장된 단결정의 사이즈가 점차 작아지므로, 투명도가 좋 


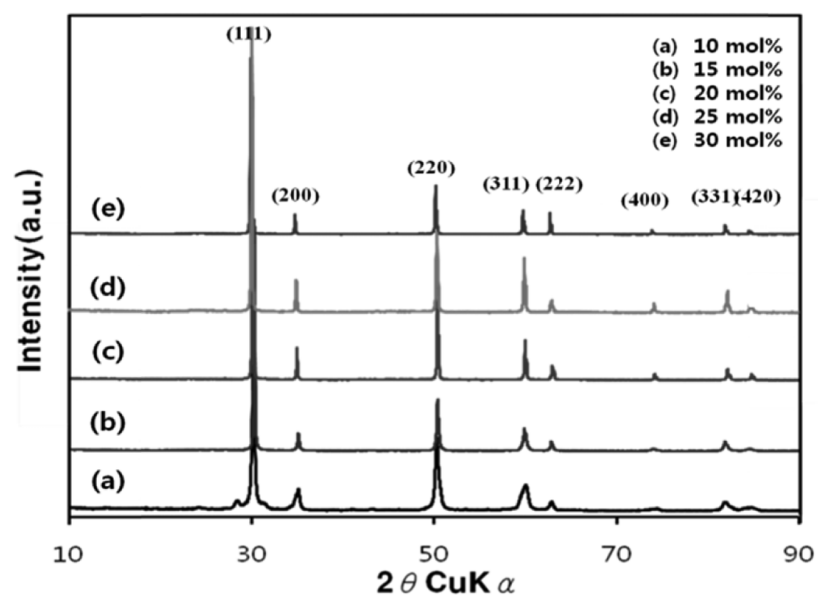

Fig. 5. XRD patterns of CaO-stabilized cubic zirconia single crystals. $\mathrm{CaO}$ amount used as stabilizer were as follows: (a) 10 mol\%, (b) $15 \mathrm{~mol} \%$, (c) $20 \mathrm{~mol} \%$, (d) $25 \mathrm{~mol} \%$ and (e) $30 \mathrm{~mol} \%$.

고 단결정 사이즈가 가장 큰 $15 \mathrm{~mol} \%$ 함량의 단결정이 보석용 큐빅 지르코니아로 적합하다고 사료된다.

Fig. 5에는 안정화제로서 $\mathrm{CaO}$ 를 첨가하여 합성한 큐 빅지르코니아 단결정에 대한 XRD 분석결과를 나타내었 다. 이 결과로부터 $\mathrm{CaO}$ 의 첨가량에 상관없이, 합성한 단결정은 단일상의 순수한 큐빅구조임을 알 수 있다. 그 리고 $\mathrm{CaO}$ 의 함량이 $10 \mathrm{~mol} \%$ 에서 $15 \mathrm{~mol} \%$ 로 증가할 때 (111)면 과 (200)면 피크의 강도가 증가하였다. 이것 은, $\mathrm{Ca}$ 이온이 2 가 상태로 치환이 되어 산소 공공이 형 성되며, 이온반경이 $\mathrm{Zr}^{4+}$ 이온에 비해 약간 큼에 따라 (200)면의 피크 강도가 증가한 것으로 판단된다. Fig. 6 에는 $\mathrm{CaO}$ 함량변화가 큐빅지르코니아 (111)면의 면간거 리에 미치는 영향을 나타내었다. $\mathrm{CaO}$ 함량이 $10 \mathrm{~mol} \%$ 에서 $15 \mathrm{~mol} \%$ 로 증가할 때 면간거리는 크게 변함이 없 었으나, $15 \mathrm{~mol} \%$ 이상 첨가할 경우 거의 직선적으로 면

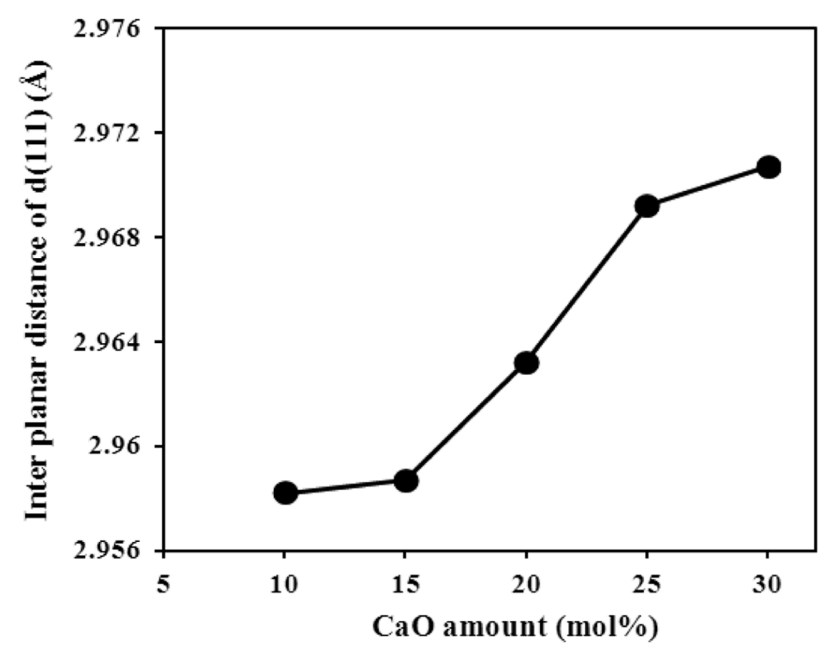

Fig. 6. Effect of $\mathrm{CaO}$ amount on the interlayer spacing $(d(111))$ of cubic zirconia single crystals.

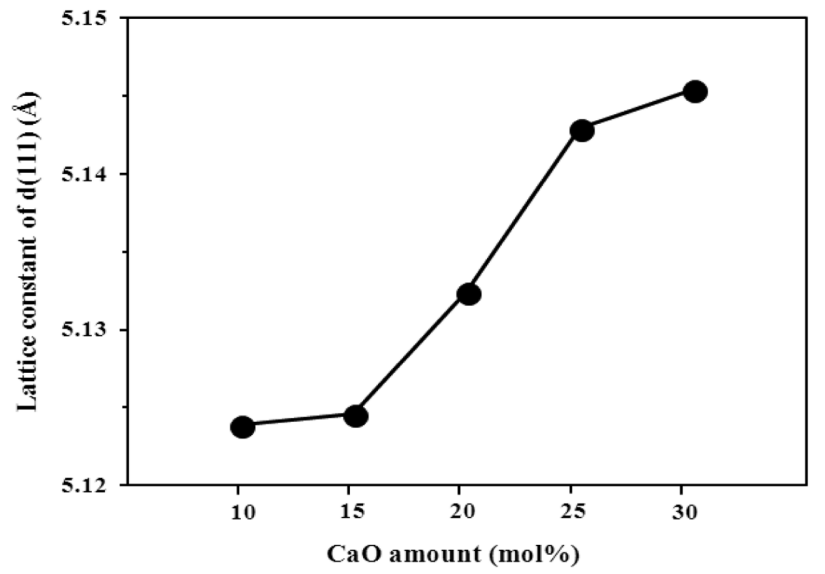

Fig. 7. Effect of $\mathrm{CaO}$ amount on the lattice constant $(\mathrm{d}(111))$ of cubic zirconia single crystals.

간거리가 증가하는 것을 알 수 있다. Fig. 7 에는 $\mathrm{CaO}$ 첨가량 변화에 따른 큐빅지르코니아의 격자상수 변화를 나타내었다. 이 결과로부터 알 수 있듯이 면간거리의 결 과와 흡사하게 $\mathrm{CaO}$ 첨가량이 증가할수록 격자상수 값이 커졌다.

즉, $\mathrm{CaO}$ 의 첨가량이 증가함과 더불어 치환되는 $\mathrm{Ca}$ 량 이 급속히 증가하였기 때문에 면간거리 및 격자상수가 증가한 것으로 판단된다. Fig. 8 에는 $\mathrm{CaO}$ 첨가량이 결 정자의 크기에 미치는 영향을 나타내었다. 결정자의 크 기는 Scherrer식을 이용하여 구했다(식 3-4).

여기서, $\beta$ 는 회절선의 반치폭(FWHM)으로부터 구하였 으며, $\mathrm{K}$ 는 형상인자로 0.9 또는 1.84 이였다. $10 \mathrm{~mol} \%$ 의 $\mathrm{CaO}$ 를 첨가할 경우, 약 $42 \AA$ 의 결정자크기를 가지고 있 었으며, $15 \mathrm{~mol} \%$ 에서 $55 \AA$ 까지 증가하였다. 그리고 15 $\mathrm{mol} \%$ 이상의 $\mathrm{CaO}$ 를 첨가할 경우 결정자 크기는 거의 수직적으로 증가하였으며, $30 \mathrm{~mol} \%$ 에서는 $101 \AA$ 까지 크 기가 증가하였다. 이상과 같이 안정화제로 사용한 $\mathrm{CaO}$

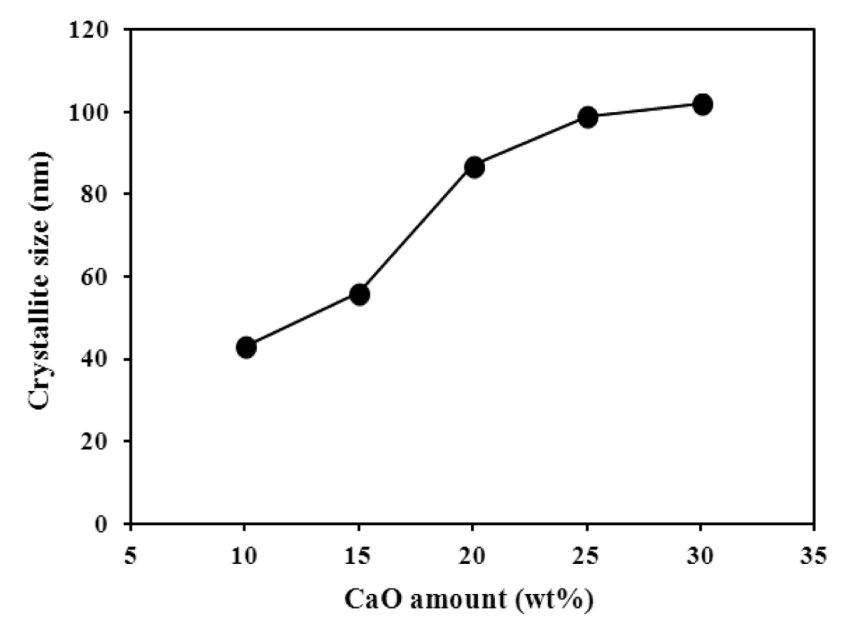

Fig. 8. Effect of $\mathrm{CaO}$ amount on the crystallite size $(\mathrm{d}(111))$ of cubic zirconia single crystals. 
함량이 증가할수록 격자상수, 면간거리 및 결정자크기가 증가하는 것을 알 수 있었다. 이것은 모결정에 안정화제 로 첨가된 $\mathrm{Ca}^{2+}$ 이온이 증가함에 따라 $\mathrm{Zr}^{4+}$ 이온의 위치 에 치환이 되어 산소 vacancy 의 생성이 증가하게 되며, 그에 따른 ligand field energy의 변화를 가져오며 $\mathrm{Ca}^{2+}$ 이온이 $\mathrm{Zr}^{4+}$ 이온보다 크기 때문에 격자 상수 및 면간거 리가 증가하였으며, 이로 인해 모결정 내부에 crystal field energy의 변화를 초래한 것으로 판단 된다.

\section{4. 결 론}

본 연구에서는 꼬막 패각을 이용하여 $\mathrm{CaO}$ 를 제조하고 제조된 $\mathrm{CaO}$ 를 안정화제로 사용하여 큐빅 지르코니아를 합성하였다. 꼬막 패각은 $1 \mathrm{~mol} \%$ 의 $\mathrm{HCl}$ 에 12 시간 처리 후 $1200^{\circ} \mathrm{C}$ 에서 5 시간 소성하였을 때 불순물이 가장 효 과적으로 제거되었다. 소성한 $\mathrm{CaO}$ 를 $45^{\circ} \mathrm{C}$ 의 온도에서 24 시간 동안 습식 수화반응시켜, 이를 다시 $1200^{\circ} \mathrm{C}$ 에서 5시간 동안 열처리했을 때 순도 $95 \sim 96 \mathrm{~mol} \%$ 의 $\mathrm{CaO}$ 를 제조할 수 있었다. 제조된 $\mathrm{CaO}$ 안정화제를 $15 \mathrm{~mol} \%$ 첨 가 하였을 때 큐빅 지르코니아의 투명도와 결정성이 가 장 좋았다. Skull melting법에 사용된 최적의 조건은 2turn coil이었으며, tank condenser는 $2000 \mathrm{pF}$, 고주파 발진기의 주파수는 약 $3.4 \mathrm{MHz}$ 이다.

\section{감사의}

이 논문은 동신대학교 학술연구비에 의하여 연구되었음.

\section{참 고 문 헌}

[1] K. Nassau, "Gems made by man", Chilton Book Co., (Randor, PA. 1980) 232.

[2] D.S. Chung and K.K. Orr, "Cubic $\mathrm{ZrO}_{2}$ single crystal growth by skull method: effect of melt homogenization in crystallization", J. Korean Ceramic Society, 27(5) (1990) 598.

[ 3 ] M.A. Taylor, Chr. Argirusis, M. Kilo, G. borchardt, K.D. Luther and W. Assmus, "Correlation between ionic radius and cation diffusion in stabilized zircon-ia", Solid State Ionics 173 (2004) 51.

[ 4 ] R.I. Merino, V.M. Orera, O. Povill, W. Assmus and E.E. Lomonova, "Optical and electron paramag netic resonance characterization of $\mathrm{Dy}^{3+}$ in YSZ single crystals", J. Phys. Chem. Solids 58(10) (1997) 1579.

[ 5 ] C.H.L. Goodman, "Crystal growth", Vol. 1 (plenumpress, New York, London, 1980) 109.

[6] S.H. Kim, J.K. Choi, D.S. Chung and K.K.Orr, "Colored cubic zirconia (CCZ) single crystal growth by skull method", J. Korean Ceramic Society 25(5) (1988) 443.

[7] I. Kim, A extracting method of calcium using Oyster Shell, Korean Patent Publication. 88-1529 (1988).

[8] I.-G. Lee, A Study on the synthesis of high purity calcium compounds using the shell resources (2000).

[9] A.W.D. Hills, "The mechanism of the thermal decomposition of calcium carbonate”, Chem. Eng. Sci. 23 (1968) 297.

[10] M.S. Lee, "A mathematical model of rotary kiln for the calcination of limestone", J. of Kor. Inst. Met. \& Mater. 35(12) (1997) 1724. 